Article

\title{
Stripping the Wallpaper of Practice: Empowering Social Workers to Tackle Poverty
}

\author{
Claire McCartan ${ }^{1}{ }^{*}$, Aine Morrison ${ }^{2}$, Lisa Bunting ${ }^{1}$, Gavin Davidson ${ }^{1}$ and Jackie McIlroy ${ }^{2}$ \\ 1 School of Social Sciences, Education and Social Work, Queen's University Belfast, Belfast BT7 1NN, \\ Northern Ireland; 1.bunting@qub.ac.uk (L.B.); g.davidson@qub.ac.uk (G.D.) \\ 2 Office of Social Services, Department of Health, Belfast BT4 3SQ, Northern Ireland; \\ aine.morrison@health-ni.gov.uk (A.M.); jackie.mcilroy@health-ni.gov.uk (J.M.) \\ * Correspondence: c.j.mccartan@qub.ac.uk; Tel.: +44-028-90975296
}

Received: 31 August 2018; Accepted: 10 October 2018; Published: 12 October 2018

\begin{abstract}
The relationship between deprivation and health and educational inequalities has been well evidenced in the literature. Recent UK research has now established a similar social gradient in child welfare interventions (Bywaters et al. 2018) with children living in the most deprived areas in the UK facing a much higher chance of being placed on the child protection register or in out-of-home care. There is an emerging narrative that poverty has become the wallpaper of practice, "too big to tackle and too familiar to notice" (Morris et al. 2018) and invisible amid lack of public support and political will to increase welfare spending. This paper will examine poverty-related inequalities and how these affect families. It will discuss the importance of recognising that poverty is a social justice issue and a core task for social work and outline the range of supports that may be available for families to help lift them out of poverty. Finally, it will describe the development of a new practice framework for social work in Northern Ireland that challenges social workers to embed anti-poverty approaches in their practice. The framework emphasises that poverty is a social justice issue, seeks to provide practical support and guidance to re-focus attention, debate, and action on poverty in times of global economic uncertainty and give social workers the tools to make it central to their practice once again. It reinforces the need for social workers to understand and acknowledge the impact of poverty, and to advocate for and support those most in need. It aims to challenge and empower professionals to tackle poverty and inequality as an aspect of ethical and effective practice.
\end{abstract}

Keywords: poverty; child protection; child welfare; inequalities; public welfare; public assistance; income support

\section{Introduction}

The social determinants of health, education, and economic outcomes have been well documented (Lee and Burkam 2002; Marmot et al. 2010; Wilkinson and Pickett 2006). Recent UK evidence has also quantified the relationship between deprivation and child welfare interventions, finding that a child's chances of becoming looked after or being placed on the child protection register (or subject to a child protection plan) greater for those living in the most deprived areas of the UK (Bywaters et al. 2018). Despite this, poverty has become the wallpaper of social work practice, "too big to tackle and too familiar to notice" (Morris et al. 2018, p. 370) during a sustained period of economic recession, public spending cuts and little public or political will to increase welfare expenditure. This paper will examine poverty-related inequalities and how these affect families. It will discuss the importance of recognising that poverty is a social justice issue and outline the range of supports that may be available for families to help lift them out of poverty. Finally, it will describe the development of a new Anti-Poverty Practice Framework for Social Work in Northern Ireland (NI) that challenges social workers to embed 
anti-poverty approaches in their practice. Arising from research funded by the Nuffield Foundation, (the Child Welfare Inequalities Project (CWIP) (Bywaters et al. 2015, 2016a, 2018)), the Department of Health in NI has developed this new framework to emphasise that tackling poverty should be a central objective of social work practice and demonstrates a commitment to social justice. It seeks to provide practical support and guidance to re-focus attention, debate, and action on poverty in times of global economic uncertainty and give social workers the tools to make it central to their practice once again.

\section{The Problem of Poverty}

Poverty can have both direct and indirect consequences for the health and wellbeing of children and families. Not all children experiencing poverty will face abuse and neglect but the interaction of poverty with other risk factors can increase their chances of maltreatment (Bunting et al. 2018). The evidence is compelling: children born in the poorest areas of the UK are more likely to die in the first year, weigh on average $200 \mathrm{~g}$ less, be bottle fed, have tooth decay, breathe second-hand smoke, become overweight, suffer from asthma, and die in an accident compared to those living in the most affluent areas (Roberts 2012). Financial strain can prevent parents from affording the basic essentials necessary for healthy growth and development and put pressure on family relationships and parenting capacity (Bywaters et al. 2016b). Poverty can subject children to poor nutrition, poor housing, inadequate heating, and clothing, and creates stress that can compromise mental and physical wellbeing. By the age of three, poorer children are estimated to be cognitively nine months behind children from more wealthy backgrounds and, by age 16, children receiving free school meals achieve 1.7 grades lower at the General Certificate of Secondary Education (GCSE) (Child Poverty Action Group 2018). Mental health problems in children including anxiety and depression are more prevalent in deprived areas (Elliott 2016). The effects of poverty on brain development can be apparent in infancy but there is growing evidence that these negative effects can be mitigated or reversed through targeted parenting interventions and poverty alleviation (Blair and Raver 2016). Poverty damages children but its effects can be reduced if appropriate action is taken.

Some families are disproportionately at risk, as a result of poverty-related inequality. According to a recent Gingerbread report (Rabinradkumar 2018), one third of children living with a working lone parent are in relative poverty. Lone parents are more likely to be trapped in low paid work and the number on zero-hour contracts has risen ten-fold between 2008-2018. One in ten have relied on last resort steps, such as payday lenders, loan sharks and food banks. Mothers on low incomes often rely on informal child care support that does not qualify for government subsidies or have non-standard work patterns that formal care cannot support (Edin and Kissane 2010). Many welfare programmes that support maternal employment can lead to positive outcomes for school-aged children's academic achievement, behaviour and health (e.g., subsidised child care, preschool provision, afterschool clubs), however, there is also contrasting evidence linking maternal shift work and transient employment to negative behavioural outcomes in young children (Han 2008; Joshi and Bogen 2007). Families with disabled children are 50 per cent more likely to be in debt and unable to afford holidays, new clothes, school outings or treats for their children (Tinson et al. 2016). Children in larger families have an increased risk of poverty because the UK tax and benefit system favours small families over larger ones (Bradshaw et al. 2006). In 2004/05, 50 per cent of children in 4+ families were poor compared to 23 per cent of one-child families (Bradshaw et al. 2006). Parents in low-income neighbourhoods tend to have low levels of social support and are less likely to access formal services. This is perhaps less true for some deprived areas of NI where families tend to live and/or work in close proximity of extended family and friends and rely heavily on them for economic and social support (Daly and Kelly 2015).

Even for families who secure steady employment, this may not lead to economic self-sufficiency but generate 'working poor' or 'in-work poor' households. Many have entry-level jobs in the service sector, work part-time, for minimum wage and do not qualify for workplace benefits. Many also continue to work informally, sell personal belongings for cash, rely on family and charities for support. To avoid in-work poverty there must be: (a) enough adults in the household working, with (b) wages 
that are not too low, and with (c) income support targeted at those who cannot survive on work alone. This is all the more difficult when only one parent is present to work and care for the family (Smeeding and Thévenot 2016). It is argued that the state has a responsibility to children if parents cannot provide an adequate income.

\section{Poverty and Social Justice}

Poverty is a social justice issue for social work. Applying Thompson's (Thompson 2016) anti-discriminatory approach to practice, poverty forms one of the structural layers of inequality that can negatively impact on an individual or family. The way poverty interacts with other inequalities (e.g., gender, race, age, disability) creates a complex setting for reflective practice that understands and responds to the power relationships that exist between social work and an individual or family. Effective anti-discriminatory practice recognises these power relationships and the multiplier effect that these inequalities can create. Being able to understand and respond effectively may take a social worker time and experience to develop these skills. McLaughlin and colleagues' (McLaughlin et al. 2017) qualitative work with Canadian social workers found that professionals with ten plus years' experience felt better equipped to link and understand social justice in practice. Their research found that newly qualified workers were preoccupied with the rules and regulations of practice and lacked the self-confidence and ability to incorporate a social justice approach in their work. Gasker and Vafeas (Gasker and Vafeas 2003) identified a fatalistic attitude in younger social workers, who underestimated their ability to effect change. Failure to understand the complex nature of poverty-related inequality may have a direct impact on child welfare interventions. Neglect is now the most cited reason for a child being subject to a child protection plan in England and Wales (Bentley et al. 2018) and current UK child protection policy seems to be driven by learning from individual child protection cases (Featherstone et al. 2016) and designed to reduce individualized risk (Davidson et al. 2017) rather than reduce the inequalities that increase the chances of neglect and abuse. As Featherstone and colleagues point out, "Comparatively speaking, many more children and young people are dying from what would appear to be avoidable reasons such as poverty and associated issues." (Featherstone et al. 2016, p. 10).

For those families who cannot afford to provide adequate food, clothing or shelter, there is a danger that poverty is mistaken for neglect (Turcios 2009). Social workers committed to social justice must understand the difference and work towards reducing inequality. Gupta and colleagues' (Gupta et al. 2018) qualitative work highlights the importance of recognising and respecting the experiences, knowledge and skills of families in the child protection system. Testimonies from families with lived experience gave powerful examples of bias and exemplified the significance of unequal power relationships within the child protection system. From the outset, parents expressed fear that their children would be removed from their care and were faced with practitioners who showed a lack of understanding and empathy and did not appreciate parents' emotional responses as normal when feeling under threat. Nor was there any acknowledgement of the shame associated with state intervention into family life. Often referrals to parenting programmes or psychotherapy seek to change behavior rather than tackle the root causes of the problems, e.g., material deprivation (Zilberstein 2016). As one of the participants in the Gupta study illustrates, social work is "one of the most intimate relationships [individuals] have with the state" (Gupta et al. 2018, p. 255). Social workers have a lot of power, they have access to highly sensitive and intimate knowledge about a person's: sex life and history, mental health, childhood events, income, education level, children's needs, and have the power to make unannounced home visits where deemed necessary.

Another issue of central importance for social justice in child welfare is the right to family life and relational identity, from both the parent and child's perspectives. Featherstone et al. propose a social model for supporting families and protecting children, acknowledging that "children's rights are interwoven and inseparable from those of their parents and family" (Featherstone et al. 2016, p. 18); it is a model that asks what the family needs to thrive and one which upholds their human rights. With so many children living in poverty in the UK, even more children and families are exposed to the 
inequalities associated with deprivation. It is important that social workers are supported in policy and practice to understand how poverty can affect or influence their decision-making, encourage them to be reflective, and feel equipped and empowered to respond to the challenges that deprivation creates for children and families.

\section{The Politics of Welfare}

While the relationship between poverty and inequality is evident, policy, and welfare reform has had great difficulty addressing it effectively. In 2000, Tony Blair's Labour government pledged to halve child poverty in a decade and eradicate it in a generation. Specific targets were set across government departments to increase income supplements, employment, child care and education support and by 2010, the absolute poverty rate had almost halved. The economic crisis of 2008 and Labour's subsequent general election loss in 2010 resulted in the formation of the Conservative/Liberal Democrat coalition government and a subsequent Conservative government which changed direction from targets to reduce poverty (increasing income from work and government through benefits, tax credits and affordable child care) towards tackling 'drivers of poverty' (family breakdown, poor education, substance misuse, and worklessness). In 2015, a $£ 12$ million welfare budget cut led to the Chancellor's pledge to take the UK from a 'low wage, high tax, high welfare economy' to a 'higher wage, lower tax, lower welfare country'. Whilst the introduction of the Universal Credit was welcomed (replacing six existing means-tested benefits and tax credits for working age people with one benefit), there has been criticism over how it has been rolled out (Timmins 2016), with lone working parents expected to be worst hit by the changes. The Institute for Fiscal Studies anticipates that the new two-child limit of the Universal Credit will contribute a further 600,000 children living in absolute poverty by 2020/21 (Institute for Fiscal Studies 2016). The current freeze on UK benefit payments has meant that relative income has been reduced putting additional financial pressure on families (Schmuecker 2017).

It is apparent that child poverty is a global concern and extensive policy and legislative commitments have been made to reduce it by individual nations, international political and economic unions (e.g., European Union (EU)), and non-governmental organisations (e.g., United Nations Children's Fund (UNICEF), the World Bank). Analysis by the Children's Defense Fund (2015) concluded that investment in existing programmes and policies could reduce child poverty in America by 60 per cent, lifting 6.6 million children out of poverty, and 500,000 extremely poor out of poverty. Solutions to reducing or ending child poverty in many rich nations "already exist if we are willing to invest in them. We must create that public will."(Wright Edelman 2016, p. S7).

Despite these commitments, welfare spending is political. People are much more resistant to welfare spending compared to other types of government expenditure (Campbell 2016) and support for it has experienced a long-term decline (although over the last five years there has been a small reversal in support). UK Data from 2014, found that only 30 per cent of people agreed that more should be spent on welfare (compared to 61 per cent in 1989 (British Social Attitudes Survey)) (Taylor-Gooby and Taylor 2014). Support for government wage top-ups for low earnings was much more popular for single parents (70 per cent) compared to working couples with children (58 per cent) and working couples without children (31 per cent) (Kelley et al. 2017). Welfare spending also reflects political party affiliations, those identifying with the centre-left Labour Party being more likely to support additional welfare than Conservative voters on the right. Seventy-one per cent of Conservative Party identifiers believed that unemployment benefits were too high and discouraged work (versus 30 per cent of Labour affiliates) (Taylor-Gooby and Taylor 2014). Perhaps welfare is considered to be a disincentive to work, but there is evidence too of prejudice against those most likely to benefit. Higher taxation may be resented by those who can see no direct benefit and perceptions about the causes of poverty (individual versus structural) can also influence societal responses.

How welfare is framed in policy may foster negative views (Campbell 2016). Huber and Paris' experiment concluded that 'assistance to the poor' is more acceptable than 'welfare' even though 
they might refer to the same thing (Huber and Paris 2013). Social judgements are often made about who are the 'deserving poor' (Cousins 2013), whether the unemployed are 'lazy' (Robinson 2010) or whether parents are 'fit' to parent (Campion 2005). While there is bias in the general public, it also exists within the child protection system (Bywaters et al. 2016a; Featherstone et al. 2017) and conservative and right-wing media can reinforce these messages (Davies et al. 2010). Davidson and colleagues (Davidson et al. 2017) apply perspectives from political theory, moral philosophy, and psychology to explore why current approaches to child welfare do not effectively address inequalities concluding that current policy is focused on individual risk and protection and 'troubled families', many people are unaware of the extent of inequalities and that political distance has been created between voting/policy behaviour and how social work functions in society.

Helping people out of poverty is a humanitarian and social justice issue as well as a child protection concern but there is also a compelling economic argument to generate support for ensuring all families have access to a basic income level (Fajth et al. 2012). Providing a guaranteed level of income gives people the means to protect themselves against economic shocks, to plan, invest, and save which, in turn, can move them from dependency into self-reliance, benefiting the entire economy. Asset building and income generation schemes are fundamental to many aid programmes in developing countries and welfare could be reframed to promote this view. The safety net that welfare assistance provides reduces poverty immediately and may also have positive long-term effects that extend well into the next generation (Sherman et al. 2016).

\section{Poverty Reduction Programmes}

By reducing poverty, inequalities in child welfare would also be reduced. There are a number of programmes that already exist to help boost family income and relieve material deprivation.

\subsection{Cash Transfers}

A number of programmes have focused on the income maximisation of families living below the poverty line. These include tax transfers, tax credits, housing benefit, food vouchers, and income support and there is compelling international evidence that money affects children's outcomes. Cooper and Stewart's (Cooper and Stewart 2013) systematic review of 61 studies from the Organisation for the Economic Co-operation and Development (OECD) and EU countries found overwhelming evidence that extra household income resulted in significant positive effects for child cognitive, social and behavioural, and health outcomes. There was also evidence for better maternal health and improved home environment giving further support for the theoretical models which explain how money makes a difference: the Investment Model (families can invest money in the things their children need to thrive); and the Family Stress Model (more income reduces family stress, improves parenting, reduces the risk of exposure to toxic stress). Based on 2013 prices, provision of an additional $\$ 1000$ ( $£ 900$ ) per year was associated with significant effect sizes in cognitive and social behavioural outcomes, and maternal depression. Providing families with additional income helps them to plan and budget better, disperses money across a range of spending categories and reduces 'risky spending', e.g., on alcohol or tobacco (Jones et al. 2015). Directing payments to families with babies and children rather than teenagers (Fletcher and Dwyer 2008) may achieve better outcomes and who receives the income may count: the 'purse versus wallet' theory (Ward-Batts 2008) that mothers who receive additional money are more likely to spend it on their children. Increasing income gives families the opportunity to make their own decisions about spending, and sends a message that they are respected and trusted to do so.

Increased income can lower rates of child maltreatment (Eckenrode et al. 2014; Pelton 2015). Cancian (Cancian et al. 2013) found that mothers randomly assigned to directly receive the full child support payment of Temporary Assistance for Needy Families (TANF) were 10 per cent less likely to have a child maltreatment report than the control group. Outcomes can be better for children in out-of-home care, displaying greater placement stability for youths in non-relative foster and kinship care where there are larger monthly stipends (Pac 2017). In contrast, financial instability or precarity 
can have a direct impact on families. Hook and colleagues' (Hook et al. 2016) construction of income histories of parents with children in foster care found that two thirds of the $\mathrm{N}=15,159$ parents had experienced 'economic disconnection' (i.e. without either work or welfare) over a three-year period and these families were also the least likely to achieve reunification with their birth children. It is no coincidence that children placed in foster care are predominantly from poor families (Pelton 2015).

\subsection{Universal Benefits}

A number of universal basic income (UBI) pilots have been underway in a range of countries, including Canada, Spain, and Finland, and although formal evaluations of the trials are yet to report, the signs are positive that a UBI gives people the capacity to plan and budget, improving diet, and health and, importantly, giving people a sense of dignity (Keegan 2018). Countries with high child allowances and universal benefits provide a strong base for all families (e.g., Sweden, France, Germany, Italy) and "Countries that dedicate a greater share of their budgets to children achieve generally better outcomes in reducing child poverty" (Smeeding and Thévenot 2016, p. S72). The USA spends much less of its Gross Domestic Product on children and has one of the highest rates of child poverty in the OECD.

\subsection{Family Support}

There are many ways that government intervenes in the labour market to assist parental employment, and policies directed at supporting parents to work may have longer term family benefits but do not replace the importance of income support. However, such assistance schemes, including job training, child care subsidies, working family support schemes, and parental leave, have their limitations. Job training may take a long time to raise parents' earnings and may only have a modest impact. There is no evidence that extended parental leave is beneficial to the child and although child care subsidies can support employment and promote child wellbeing via good quality early education, much child care provision is of average quality (Currie 2016). Indeed, many successful programmes are independent of parental employment (e.g., USA Medicaid cover for poor children under 18, Supplemental Nutrition Assistance Program (SNAP), and the Special Supplemental Feeding Program for Women Infants and Children (WIC)). Although such initiatives have been proven to reduce mortality in adulthood, reduce chronic health conditions including obesity and heart disease, and reduce reliance on welfare in later life (Wherry and Miller 2016) they may be at risk under current austerity.

Countries where in-kind services facilitate work and increase income tend to achieve better outcomes than those that rely on cash provision alone (e.g., Sweden and Norway). As stated previously, for working families, it is essential to ensure a non-poor living standard for children-if not enough adults are not working enough hours, or wages are too low, work alone may be insufficient.

\subsection{Community-Based Responses}

Building community capital and responding to need on a local level can be effective. The Head Start programme in the US introduced in the mid-1960s aimed to lift children out of poverty by preparing them for school, and provided health, nutrition and parenting support. The programme has been developed and extended across the States serving over 22 million children, helping parents into employment and a large number of evaluations have linked Head Start to long term educational, health and employment benefits well into adulthood (Abbott-Shim et al. 2003; Puma et al. 2010). In the UK, the Sure Start early intervention programme targeted services at the $20 \%$ most deprived areas, offering outreach services and home visiting, support for families and parents, early childhood education, and healthcare. Evaluations of Sure Start raised concerns that it did not reach the most disadvantaged families and resources were stretched too thinly; with a focus on employability rather than the original child development agenda (Bate and Foster 2017). However, Sure Start has established the role that government needs to play between birth and school (Eisenstadt 2011). The Vibrant Communities 
initiative across 12 Canadian cities aimed to reduce poverty through multi-sectoral collaboration, action planning, building community assets, and learning and change (Cabaj et al. 2015). The key to its success lay with the engagement of local leaders (Trail Builders) from the private, public, and voluntary sectors and residents with lived experience to develop the vision for action and to drive efforts locally.

Reliance on community support through community and voluntary organisations is also growing. Food banks are inundated; the UK's largest food bank, The Trussell Trust reported record numbers of requests last year with their network of 428 food banks dispensing almost 1.2 million three-day emergency supplies. They have been developing pilots to improve links with government employment support JobCentre Plus offices and similar projects are underway across the UK; "Food banks are doing crucial work. But food banks cannot stop UK hunger alone" (Loopstra and Lalor 2017). The need for food banks demonstrates the pervasive extent of poverty in the UK.

In other countries, acknowledging that child protection is not the sole responsibility of any one profession has led to the development of integrated child welfare and community development practice. In Ethiopia, the pilot of the Integrated Community Development and Child Welfare Model (CD-CW) trained community development workers. This role combines the skills and responsibilities of community development with child protection to encourage asset-based development and family enterprise to increase family income coupled with trauma-informed practice with children (Butterfield et al. 2017). Work with Aboriginal children in both Canada (Chalker Place) and Australia (National Association for the Prevention of Child Abuse initiatives) has also adopted a community development approach to child protection; by helping to build a community around a child to provide greater economic and emotional security (Butterfield et al. 2017). The Whanau-Ora policy in New Zealand aims to address the intergenerational nature of poverty and the disproportionate rates of Maori child poverty (Davies et al. 2010). Establishment of the Early Years Hubs in New Zealand has led to encouraging results to co-ordinate service delivery, and the early intervention Family Support Hub model in NI may also be contributing to lower child welfare interventions rates compared to the other UK nations (Bunting et al. 2017). Other community partnerships have also been established in the UK and USA to build social networks and social capital to prevent maltreatment (Butterfield et al. 2017).

\subsection{Healthcare}

Substantial changes to healthcare delivery have been made at a local level in the United States. The introduction of paediatric practice frameworks allow for the identification and referral of children stressed by poverty. Enhanced advocacy within the healthcare system is raising awareness of poverty and pressing for policy change including minimum wage increases, expansion of tax credits, paid family leave, and universal preschool education (Racine 2016). Early years programmes have been embedded in paediatric practice in the USA, e.g., Read Out and Read, home visiting programmes, and parent mentoring programmes. Exemplar home visiting programmes build economic self-sufficiency improving parent knowledge, skills and motivation, and providing practical links to adult education and job training (Minkovitz et al. 2016). Primary care parenting interventions have the potential to reach large numbers of children (Cates et al. 2016) and the American Academy of Pediatrics has been vocal in policy, legislation, education and leadership (Beck et al. 2016), clearly demonstrating a strong and dynamic advocacy role for their members. This is a good example of how professionals in the health and social care sectors can address social justice and inequality beyond the confines of policy or limited resources.

GPs in the UK have been involved in a number of pilot schemes designed to identify and respond to poverty including a fuel poverty referral scheme in Wiltshire (Eadson et al. 2017), food prescriptions (Pasha-Robinson and Matthews-King 2017) and plans are underway in NI to embed a community social worker within primary care GP practices. The British Medical Association has also encouraged doctors to become community leaders and activists and use their advocacy skills to lobby for resources 
or contribute to policy development while providing direct support to patients, including the role that social prescribing can play (British Medical Association 2017).

\section{Barriers}

Factors can limit the reach and depth of services include poor interdisciplinary working, proximity of services, leadership, and the lack of lived experience of poverty. Poverty is not equally distributed among neighbourhoods and improving access to good transport, quality housing, affordable child care and nutrition, and health services would help to reduce inequalities (Davies et al. 2010). Community cohesion and social capital within a neighbourhood are important support networks for families and many low-income areas do not have high levels of community capital. Even when children are relocated from low-income neighbourhoods to be housed and educated in more affluent areas, the lack of a social network can impede their efforts to engage in services (Keels 2013). Attrition rates in family treatment programmes can be high with at-risk populations suggesting that services need to be designed to encourage participation (De Haan et al. 2013). Further, programmes designed for those most in need may not be reaching their target population. Gilbert and colleagues' (Gilbert et al. 2014) analysis of social support programmes for at-risk families in poverty, e.g., TANF, SNAP, and MAP assessed whether recipients were simultaneously enrolled across the available schemes. Of the $\mathrm{N}=23,065$ families 100 per cent below the federal poverty level (on an average income of $\$ 10,160$ ), only 8 per cent were claiming all three benefits, and 28 per cent were not enrolled on any programme. Gilbert concluded that "enrolment in these programmes is often uncoordinated, with differing and complicated administrative requirements leading to inconsistent services and reduced participation" (Gilbert et al. 2014, p. 605). Barriers that prevent enrolment include stigma, clinic based (waiting list delays), perceived eligibility, logistics (transport, child care), English as an additional language, distrust of government, and homelessness (Gilbert et al. 2014). In the UK, Sure Start has been criticised for not delivering to those most in need (Bate and Foster 2017). In NI, the Department for Communities 'Make the Call' benefit uptake programme has targeted households to receive a benefits entitlement check. Additional benefits of $£ 21.3$ million were generated for 4810 people in 2016/17, leading to on average an extra $£ 85$ per week (Department for Communities 2017).

Arguably social work education has moved away from addressing poverty, policy analysis, and community organisation towards a greater emphasis on the psychotherapeutic approaches (Castillo and Becerra 2012). Social work needs help to understand how policy is framed and consider the importance of the safety net that government and community provides. The social work role should include political campaigning and advocacy, "social workers and social welfare advocates first and foremost must continue to work diligently to shape policies and programs as opposed to largely implementing and administering them" (Cousins 2013, p. 1257). In NI, practice had largely disengaged from political analysis because of the tensions between state and civil society (Das et al. 2016) and requires a redefinition of the partnerships between statutory and community sectors, and the development of new partnerships with community organisations.

\section{Child Welfare Interventions in NI}

The CWIP found a statistically significant social gradient between neighbourhood deprivation and the proportion of children on the child protection register or being looked after in all four nations of the UK. Child welfare intervention rates were lower in NI compared to the rest of the UK. This is despite higher levels of deprivation, a larger proportion of children living in deprived neighbourhoods, and higher referral rates to Children's Services. These findings suggest that the context and practice in NI may be different to GB and qualitative work is currently underway using the same methodology as Morris et al. (2018) to explore why rates are comparatively lower. Closer proximity to poverty, integrated health and social care services, a strong community and voluntary sector born out of the Troubles, and the role of the Family Support Hubs may all contribute to lower child welfare intervention rates; the team are due to report on findings in early 2019. The CWIP findings have stimulated debate 
across each of the four nations, and in NI this was led by the Department of Health NI's Office of Social Services (OSS). With clear evidence provided by the CWIP data and growing evidence from practice, the OSS sought to respond to the findings by looking more closely at how poverty informs practice and challenges the profession to think and understand better how the multi-dimensional nature of poverty affects people. Applying the inequalities lens, familiar within healthcare and education, to understand child welfare interventions encourages social work to confront individual, structural, and systemic inequalities in policy and practice, and presents an opportunity for reflection, empathy, advocacy, and a renewed commitment to social justice.

\section{An Anti-Poverty Practice Framework}

The OSS is a small branch of the Department of Health in NI staffed by professional social workers who have considerable previous operational experience in delivering social work and social care services. The Office has a varied remit including the provision of professional advice and input to the formulation and implementation of government policy in respect of social care services and related social policy and professional practice matters. The OSS has oversight responsibilities for social work training in NI and is the sponsorship body for the NI Social Care Council who are the regulatory body for social work and social care.

In 2018, the OSS decided to launch a Reflections series. The Reflections series aims to support social workers in their practice and is designed to provoke thought and stimulate a conversation with and within the social work community in NI. It very deliberately does not have the status of formal government policy and procedure and does not introduce new requirements for practice. However, it is intended to be an influential "reflection" which will inform and encourage critical thinking. The first of the Reflections series was an Anti-Poverty Practice Framework for Social Work in Northern Ireland (Department of Health NI 2018). The decision to produce an anti-poverty framework was prompted by a number of developments. Firstly, social workers on the ground were telling the OSS about rising levels of poverty, including evidence of extreme poverty and severe hardship at levels not previously seen. This included issues such as an increasing dependence on food banks, holiday hunger, poor housing conditions and debt. Secondly, the OSS was very struck by the findings from the CWIP. Evidence that children in the most deprived ten per cent of small neighbourhoods in NI are nearly six times more likely to be on the child protection register and four times more likely to be "looked after" were stark and challenged the OSS to reflect on how much poverty and its impact on individuals, families and communities is considered in social work practice. Thirdly, the anti-poverty message chimed with a growing emphasis within the OSS on reclaiming a practice that emphasised equality and social justice. The OSS recognised that the weight of the demands on the social work profession could lead to a focus on process and the transactional; do the assessment, fill in the right form, get the care package in place, hold the review, and close the case approach. The OSS was aware that this can feel mechanistic and deeply dissatisfying for service users and social workers both. Developments in NI including a new role for social work in primary care and a new post-qualifying course in community social work had the potential to create a space for practice that would be more holistic and systemic and concentrate on the causation of people's problems.

The OSS set up a steering group to guide, advise and support the work of developing an anti-poverty practice framework. Steering group membership included service user representation, the advice sector, the community and voluntary sector, social work academics from Queen's University Belfast, front-line social work practitioners, Department for Communities NI representation, OSS staff and two of the five Executive Directors of Social Work in NI's Health and Social Care Trusts. The group as a whole had considerable breadth of experience, expertise and perspective which was of immense value to the work.

The framework seeks to bring poverty into the foreground of social work practice. It was agreed that while social workers in both children and adult services instinctively know that many of those they work with do experience poverty and deprivation, it was so commonplace that it risked becoming 
the "wallpaper of practice: too big to tackle and too familiar to notice" (Morris et al. 2018, p. 370), slipping into the background, not featuring in assessments of contributory factors and not seen as something to address. The framework aims to help social workers both recognise and respond to the impact of poverty on the people they support. The framework is also very clear that social work, as a profession committed to social justice, must address the injustice of poverty.

A decision was made to divide the framework into two sections, a recognition and a response section. The Recognition section aims to give social workers in NI key facts, figures and evidence about the impact on poverty on the various client groups they support. This part includes sections on poverty and caring, poverty and mental health, poverty and ethnicity, and poverty and child abuse and neglect. It aims to help social workers understand the pervasive and far-reaching nature of poverty, including the psychological impact of poverty by building on Thompson's anti-discriminatory practice (Thompson 2016) and prompting them to consider how they interact and engage with poverty and avoid contributing to inequalities. Using the testimony of ATD Fourth World project participants, the framework features direct quotations throughout from people who have experienced poverty. These raw and authentic voices greatly enrich the messages from the evidence base.

In the Response section, the framework seeks to give meaningful, realistic, and practical ideas for anti-poverty practice. The steering group had agreed that some social workers might struggle to understand poverty as part of their remit. Even where it was understood, the steering group had discussed the risk of social workers feeling powerless in the face of poverty (Carlson 2017). Indeed, one of the first debates at the steering group was what to call the framework. There was some concern that calling it an anti-poverty framework might appear too ambitious and, therefore, off-putting for social workers. However, by comparing it to anti-racist or anti-sexist or anti-homophobic practice, we agreed that the aim was conceptually the same as these other areas of anti-oppressive practice and, therefore, the term anti-poverty was appropriate and necessary.

Placing anti-poverty work firmly under the umbrella of anti-oppressive practice is an important feature of the framework. In doing so, the framework uses a concept and terminology that is very familiar to social workers and invites social workers to extend their understanding of poverty to see it as oppression. The framework uses Thompson's (Thompson 2016) personal, cultural, and structural model of oppression to give examples of how and when social workers might need to challenge the oppression of poverty. At a personal level, a social worker may need to challenge their own views that those experiencing poverty need to work harder, budget better, waste less, or reduce their expectations and question whether the demands made on service users for child protection plans, risk management plans are poverty aware. Are the expected standards of personal behaviour and self or household management poverty aware? People having difficulty engaging with services may be dealing with underlying problems that are poverty-related. At a cultural level, social workers may need to challenge underlying judgements about the 'deserving poor' and at a structural level, challenge the system, e.g., tackling structures that will not give out cash, but will give food vouchers.

This emphasis on the attitudinal is a feature of the Response section of the framework. While, it contains many helpful suggestions about practical supports, it also challenges social workers to think about how they respond to people in poverty, what judgements they make and what assumptions they rely on. Again, the use of personal testimony powerfully supports the rest of the text with a strong emphasis on the need for respect, dignity and empowerment. It includes practice ideas on co-production of responses to poverty, improving material circumstances, countering the non-material aspects of poverty, advocacy, community social work, and policy input. This includes supporting people to receive their maximum benefit entitlement, and providing sign posts to advice organisations where necessary to receive advice about fuel, heating, debt management, money advice, etc. Social workers should also be aware of their power to make cash grants, and prioritise those in poverty to access other discretionary resources. Being aware of the local organisations that can provide support can also be key. The framework also encourages professionals to consider how they can tackle the non-material aspects of poverty and encourage service users to develop confidence and skills and 
seek out options to access play, education, work, sport, holidays or social and leisure activities central to promote dignity, self-belief, and self-esteem. The advocacy skills of the social worker can also be used to counteract disempowerment of service users, and promote poverty aware practice with other professionals within their multi-disciplinary networks, "Social workers should act as leaders in tackling poverty. Leadership on this issue can occur at many different levels." (Department of Health NI 2018, p. 32). Social workers also have a role contributing to the development of policy, social work training, and research.

Careful attention was paid to the design of the document. The intention was to create a highly visual document that would be attention grabbing and easy to read. The Framework uses bright colours, infographics, quotation bubbles and bullet points throughout. Full documents, summary documents and posters were made available as hard copies and on line. Inspired by a Harry Venning cartoon drawing showing poverty as the "elephant in the room" of social work practice (see Figure 1), it was decided to extend the motif throughout the document to show a "poverty elephant" looming over mental health issues, disability issues, caring, etc. The use of this motif helped emphasise one of the key aims of the Framework which was to support social workers to recognise and name poverty as a factor in their work.

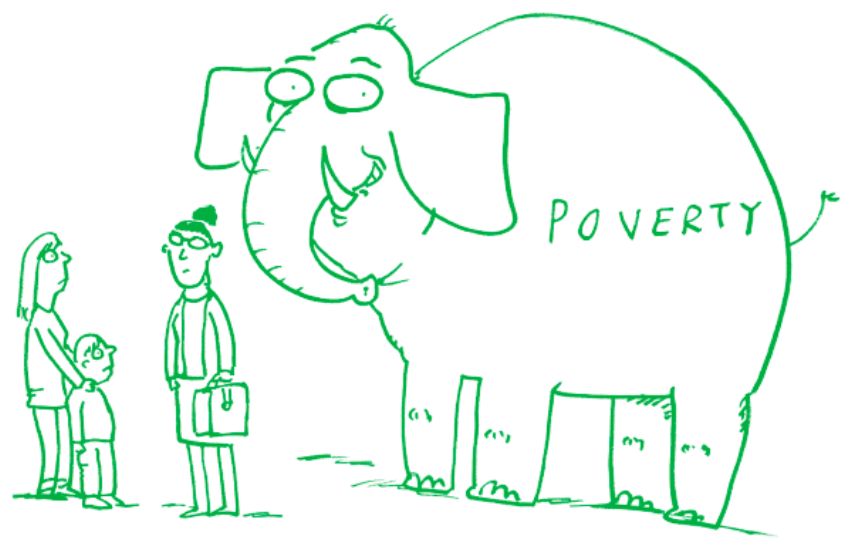

Figure 1. Poverty - the elephant in the room. Cartoon courtesy of Harry Venning.

The framework was launched by the Chief Social Worker on 3 July 2018. The Department of Health partnered with East Belfast Mission, a local faith-based organisation who focus on anti-poverty work, to hold the event. Social workers were the main target group for the audience and other agencies from the statutory, community, and voluntary sector also promoted their anti-poverty work at the event. This was an acknowledgement of the partnership needed for anti-poverty work and the need to help support social workers to network and understand what resources are available locally to help combat poverty. Distribution of the framework material is now underway and a series of awareness-raising practice seminars will take place in each of the five Health and Social Care Trusts in Autumn/Winter 2018. The support of the Executive Directors of Social Work in the five Trusts for this initiative has been an important part of the process to date and will remain key in ensuring the integration of the Framework into practice. Discussions are also underway with social work trainers and educators in NI's two local universities about integrating the framework and embedding anti-poverty practice in both under-graduate and post qualifying training. While it is too early to evaluate its impact, the initial response from the social work community in NI has been enthusiastic. The Framework has generated a lot of discussion both on and offline and it has been welcomed both as a much-needed response to poverty but also as a clear commitment to social work's place in tackling inequality and injustice. A formal evaluation is planned for approximately one year's time. 


\section{Conclusions}

This paper has outlined the multi-dimensional nature of poverty and poverty-related inequalities and the risks and negative effects it can have on children and families. It has looked at the politics of welfare and how little public and political support there is to increase spending in times of economic pressure. It has highlighted the need for poverty-aware responses in practice and given examples of the type of help and support that may be available to families. Programmes that can support families in poverty whether focusing on income support/maximisation, helping families to work and earn an adequate wage, subsidising high-quality child care, or improving parenting should focus on giving parents dignity and independence. Equipping families with an income guarantee to help them to plan, budget and cope with economic adversity is a positive aspect of welfare provision which could also substantially reduce the need for more negatively focused child welfare interventions. Aiming to reduce poverty should be the intention of policy and practice, and in doing so, help to tackle poverty-related inequality. This initiative also seeks to reassure and encourage social workers that they can do something to alleviate poverty. Social work has an important role to demand social justice. Anti-poverty practice can generate better understanding of the causes, mechanisms and impact that poverty has on families and can challenge individual responses, systems, and structures to respond with empathy, 'recognition and respect' (Gupta et al. 2018). The promotion of dignity and independence is central to the Anti-Poverty Practice Framework. It reinforces the need for social workers to understand and acknowledge the impact of poverty; and to advocate and support those most in need. It aims to challenge and empower professionals to help tackle poverty and inequality and promote social justice as an aspect of ethical and effective practice.

Author Contributions: The concept of the paper was discussed by all authors. C.M. and A.M. wrote the original draft and Claire, A.M. and G.D. reviewed and edited the final submission. Funding was secured by L.B. and J.M. L.B. was responsible for the project administration at Queen's University Belfast and Jackie McIlroy led and resourced the development of the Anti-Poverty Practice Framework on behalf of the Office of Social Services, Department of Health NI.

Funding: The Child Welfare Inequalities Project was funded by the NUFFIELD FOUNDATION, grant number KID 41935 and 'The Anti-Poverty Framework for Social Work' was funded by the Department of Health NI.

Conflicts of Interest: The authors declare no conflict of interest.

\section{References}

Abbott-Shim, Martha, Richard Lambert, and Frances McCarty. 2003. A comparison of school readiness outcomes for children randomly assigned to a Head Start Program and the Program's wait list. Journal of Education for Students Placed at Risk 8: 191-214. [CrossRef]

Bate, Alex, and David Foster. 2017. Sure Start (England). Briefing Paper Number 7257. June 9. Available online: http:/ / researchbriefings.files.parliament.uk/documents/CBP-7257/CBP-7257.pdf (accessed on 11 October 2018).

Beck, Andrew F., Megan M. Tschudy, Tumaini R. Coker, Kamila B. Mistry, Joanne E. Cox, Benjamin A. Gitterman, Lisa J. Chamberlain, Aimee M. Grace, Michael K. Hole, Perri E. Klass, and et al. 2016. Determinants of health and pediatric primary care practices. Pediatrics 2016: peds-2015. [CrossRef] [PubMed]

Bentley, Holly, Andy Burrows, Laura Clarke, Abbie Gillgan, Jazmin Glen, Maria Hafizi, Fiona Letendrie, Pam Miller, Orla O'Hagan, Priya Patel, and et al. 2018. How Safe are Our Children? The Most Comprehensive Overview of Child Protection in the UK. Available online: https:/ / learning.nspcc.org.uk/media/1067/howsafe-are-our-children-2018.pdf (accessed on 11 October 2018).

Blair, Chancy, and Cybele Raver. 2016. Poverty, stress, and brain development: new directions for prevention and intervention. Academic Pediatrics 16: S30-S36. [CrossRef] [PubMed]

Bradshaw, Jonathan, Naomi Finch, Emese Mayhew, Veli-Matti Ritakallio, and Christine Skinner. 2006. Child Poverty in Large Families. York: Joseph Rowntree Foundation.

British Medical Association. 2017. Health at A Price. Reducing the Impact of Poverty. Available online: https: / / www.bma.org.uk/collective-voice/policy-and-research/public-and-population-health/ health-inequalities (accessed on 11 October 2018). 
Bunting, Lisa, Claire McCartan, and Gavin Davidson. 2017. Identifying and Understanding Inequalities in Child Welfare Intervention Rates: Comparative Studies in Four UK Countries. Single Country Quantitative Study Report: Northern Ireland. Available online: https:/ / pure.qub.ac.uk/portal/files/126821013/NI_Country_ Report_Final_Feb_2017.pdf (accessed on 11 October 2018).

Bunting, Lisa, Gavin Davidson, Claire McCartan, Jennifer Hanratty, Paul Bywaters, Will Mason, and Nicole Steils. 2018. The association between child maltreatment and adult poverty-A systematic review of longitudinal research. Child Abuse \& Neglect 77: 121-33.

Butterfield, Alice K, James L Scherrer, and Katarzyna Olcon. 2017. Addressing poverty and child welfare: The Integrated Community Development and Child Welfare Model of practice. International Social Work 60: 321-35. [CrossRef]

Bywaters, Paul, Geraldine Brady, Tim Sparks, Elizabeth Bos, Lisa Bunting, Brigid Daniel, Brid Featherstone, Kate Morris, and Jonathan Scourfield. 2015. Exploring inequities in child welfare and child protection services: Explaining the 'inverse intervention law'. Children and Youth Services Review 57: 98-105. [CrossRef]

Bywaters, Paul, Geraldine Brady, Tim Sparks, and Elizabeth Bos. 2016a. Child welfare inequalities: New evidence, further questions. Child E Family Social Work 21: 369-80.

Bywaters, Paul, Lisa Bunting, Gavin Davidson, Jennifer Hanratty, Will Mason, Claire McCartan, and Nicole Steils. 2016b. The Relationship between Poverty, Child Abuse and Neglect: An Evidence Review. York: Joseph Rowntree Foundation.

Bywaters, Paul, Jonathan Scourfield, Chantel Jones, Tim Sparks, Martin Elliott, Jade Hooper, Claire McCartan, Marina Shapira, Lisa Bunting, and Brigid Daniel. 2018. Child welfare inequalities in the four nations of the UK. Journal of Social Work. [CrossRef]

Cabaj, Mark, Eric Leviten-Reid, Dana Vocisano, and Mabel Jean Rawlins. 2015. An example of patch evaluation. In Developmental Evaluation Exemplars: Principles in Practice. Edited by Michael Quinn Patton, Kate McKegg and Nan Wehipeihana. New York: The Guilford Press, p. 163.

Campbell, Colin. 2016. The formative years, economic hardship and beliefs about the government's role in lessening poverty. Social Problems 63: 244-65. [CrossRef]

Campion, Mukti Jain. 2005. Who's Fit to be a Parent? Abingdon: Routledge.

Cancian, Martha, Mi-Youn Yang, and Kristen Shook Slack. 2013. The effect of additional child support income on the risk of child maltreatment. Social Service Review 87: 417-37. [CrossRef]

Carlson, Juliana. 2017. 'What can I do'? Child welfare workers' perceptions of what they can do to address poverty. Journal of Children and Poverty 23: 161-76. [CrossRef]

Castillo, Jason T., and David Becerra. 2012. The perception of poverty and social welfare policties among undergraduate and graduate social work students in the United States. Journal of Human Behavior in the Social Environment 22: 375-91. [CrossRef]

Cates, Carolyn Brockmeyer, Adriana Weisleder, and Alan Mendelsohn. 2016. Mitigating the effects of family poverty on early child development through parenting interventions in primary care. Academic Pediatrics 16: S112-S120. [CrossRef] [PubMed]

Child Poverty Action Group. 2018. The Impact of Poverty. Available online: http://cpag.org.uk/content/impactpoverty (accessed on 30 August 2018).

Children's Defense Fund. 2015. Ending Child Poverty Now. Washington: Childrens Defense Fund.

Cooper, Kerris, and Kitty Stewart. 2013. Does Money Affect Children's Outcomes?: A Systematic Review. York: Joseph Rowntree Foundation.

Cousins, Linwood H. 2013. Deservingness, children in poverty, and collective well being. Children and Youth Services Review 35: 1252-59. [CrossRef]

Currie, Janet. 2016. How can we reduce child poverty and support parental employment? Academic Pediatrics 16: S13-S15. [CrossRef] [PubMed]

Daly, Mary, and Grace Kelly. 2015. Everyday Life on a Low Income. Bristol: Bristol University Press.

Das, Chaitali, Martin O'Neill, and John Pinkerton. 2016. Re-engaging with community work as a method of practice in social work: A view from Northern Ireland. Journal of Social Work 16: 196-215. [CrossRef]

Davidson, Gavin, Lisa Bunting, Paul Bywaters, Brid Featherstone, and Claire McCartan. 2017. Child welfare as justice: why are we not effectively addressing inequalities? The British Journal of Social Work 47: 1641-51. [CrossRef] 
Davies, Emma, Charles Crothers, and Kirsten Hanna. 2010. Preventing child poverty: barriers and solutions. New Zealand Journal of Psychology 39: 20-31.

De Haan, Anna M., Albert E. Boon, Joop T. de Jong, Machteld Hoeve, and Robert Vermeiren. 2013. A meta-analytic review on treatment dropout in child and adolescent outpatient mental health care. Clinical Psychology Review 33: 698-711. [CrossRef] [PubMed]

Department for Communities. 2017. The 'Make the Call' Benefit Uptake Programme. Available online: https: / / www.communities-ni.gov.uk/articles/benefit-uptake-programme (accessed on 30 August 2018).

Department of Health NI. 2018. Anti-Poverty Practice Framework for Social Work in Northern Ireland. Available online: https:/ / www.health-ni.gov.uk/sites/default/files/publications/health/Povertyframework.pdf (accessed on 11 October 2018).

Eadson, William, Tony Gore, and Larissa Povey. 2017. Evaluation of Royal College of GPS Fuel Poverty Pilot. Sheffield: Sheffield Hallam University, Centre for Regional Economic and Social Research.

Eckenrode, John, Elliott G Smith, Margaret E McCarthy, and Michael Dineen. 2014. Income inequality and child maltreatment in the United States. Pediatrics 133: 454-61. [CrossRef] [PubMed]

Edin, Kathryn, and Rebecca Joyce Kissane. 2010. Poverty and the American family: A decade in review. Journal of Marriage and Family 72: 460-79. [CrossRef]

Eisenstadt, Naomi. 2011. Despite Initial Mistakes, the Success of the Sure Start Programme Has Been to Prove that Government Does Have a Role to Play in the dEvelopment of Young Children. Available online: http:/ / blogs.lse.ac.uk/politicsandpolicy/sure-start-success/ (accessed on 28 September 2018).

Elliott, Iris. 2016. Poverty and Mental Health: A Review to Inform the Joseph Rowntree Foundation's Anti-Poverty Strategy. London: Mental Health Foundation.

Fajth, Gáspár, Sólrún Engilbertsdóttir, and Sharmila Kurukulasuriya. 2012. From comparative to global social policy: Lessons for development practitioners from UNICEF's Global Study on Child Poverty and Disparities. Children and Youth Services Review 34: 499-508. [CrossRef]

Featherstone, Brid, Anna Gupta, and Kate Morris. 2016. Let's stop feeding the risk monster: Towards a social model of 'child protection'. Families, Relationships and Societies 7: 7-22. [CrossRef]

Featherstone, Brid, Kate Morris, Brigid Daniel, Paul Bywaters, Geraldine Brady, Lisa Bunting, Will Mason, and Nughmana Mirza. 2017. Poverty, inequality, child abuse and neglect: Changing the conversation across the UK in child protection? Children and Youth Services Review. [CrossRef]

Fletcher, Michael, and Máire Dwyer. 2008. A Fair Go for All Children, Actions to Address Child Poverty in New Zealand. Wellington: Office of the Children's Commissioner.

Gasker, Janice, and John Vafeas. 2003. Starting where the student is: adapting social justice curricula to poverty attitudes. Journal of Baccalaureate Social Work 9: 93-112. [CrossRef]

Gilbert, Danielle, Joy Nanda, and David Paige. 2014. Securing the safety net: concurrent participation in income eligible assistance programs. Maternal and Child Health Journal 18: 604-12. [CrossRef] [PubMed]

Gupta, Anna, Hannah Blumhardt, and ATD Fourth World. 2018. Poverty, exclusion and child protection practice: the contribution of the 'politics of recognition \& respect'. European Journal of Social Work 21: 247-59.

Han, Wen-Jui. 2008. Shift work and child behavioral outcomes. Work, Employment and Society 22: 67-87. [CrossRef] [PubMed]

Hook, Jennifer L., Jennifer L Romich, JoAnn S. Lee, Maureen O. Marcenko, and Ji Young Kang. 2016. Trajectories of economic disconnection among families in the child welfare system. Social Problems 63: 161-79. [CrossRef]

Huber, Gregory A., and Celia Paris. 2013. Assessing the programmatic equivalence assumption in question wording experiments: understanding why Americans like assistance to the poor more than welfare. Public Opinion Quarterly 77: 385-97. [CrossRef]

Institute for Fiscal Studies. 2016. Living Standards, Poverty nd Inequality in the UK: 2015-16 to 2020-21. Available online: https: / / www.ifs.org.uk/publications / 8171 (accessed on 11 October 2018).

Jones, Lauren, Kevin Milligan, and Mark Stabile. 2015. Child Cash Benefits And Family Expenditures: Evidence From The National Child Benefit. Working Paper 21101. Cambridge: National Bureau of Economic Research.

Joshi, Pamela, and Karen Bogen. 2007. Nonstandard schedules and young children's behavioral outcomes among working low-income families. Journal of Marriage and Family 69: 139-56. [CrossRef]

Keegan, Matthew. 2018. Benefit or burden? The cities trying out universal basic income. The Guardian, June 27.

Keels, Micere. 2013. The importance of scaffolding the transition: Unpacking the null effects of relocating poor children into nonpoor neighborhoods. American Educational Research Journal 50: 991-1018. [CrossRef] 
Kelley, Nancy, Christopher Warhurst, and Robbie Wishart. 2017. Work and welfare: the changing face of the UK labour market. In British Social Attitudes, 35th ed. London: NatCen.

Lee, Valerie, and David Burkam. 2002. Inequality at the Starting Gate: Social Background Differences in Achievement as Children Begin School. Washington: Economic Policy Institute.

Loopstra, Rachel, and Doireann Lalor. 2017. Financial Insecurity, Food Insecurity, and Disability: The Profile of People Receiving Emergency Food Assistance From The Trussell Trust Foodbank Network in Britain. Salisbury: The Trussell Trust.

Marmot, Michael G., Jessica Allen, Peter Goldblatt, Tammy Boyce, Di McNeish, Mike Grady, and Ilaria Geddes. 2010. Fair Society, Healthy Lives: Strategic Review of Health Inequalities in England Post-2010. Available online: http:/ / www.instituteofhealthequity.org/resources-reports / fair-society-healthy-lives-the-marmotreview / fair-society-healthy-lives-full-report-pdf.pdf (accessed on 11 October 2018).

McLaughlin, Anne Marie, Erin Gray, and Maureen Wilson. 2017. From tenuous to tenacious: Social justice practice in child welfare. Journal of Public Child Welfare 11: 568-85. [CrossRef]

Minkovitz, Cynthia S., Kay O'Neill, and Anne K Duggan. 2016. Home visiting: a service strategy to reduce poverty and mitigate its consequences. Academic Pediatrics 16: S105-S111. [CrossRef] [PubMed]

Morris, Kate, Will Mason, Paul Bywaters, Brid Featherstone, Brigid Daniel, Geraldine Brady, Jade Hooper, Nughmana Mirza, Jonathan Scourfield, and Calum Webb. 2018. Social work, poverty, and child welfare interventions. Child E Family Social Work 23: 364-72.

Pac, Jessica. 2017. The effect of monthly stipend on the placement instability of youths in out-of-home care. Children and Youth Services Review 72: 111-23. [CrossRef]

Pasha-Robinson, Lucy, and Alex Matthews-King. 2017. Help a hungry child: NHS docts to pilot food prescriptions as poverty soars. The Independent. Available online: https:/ / www.independent.co.uk/helpahungrychild/ doctors-nhs-food-prescriptions-pilot-poverty-soars-a8119221.html (accessed on 11 October 2018).

Pelton, Leroy. 2015. The continuing role of material factors in child maltreatment and placement. Child Abuse $\mathcal{E}$ Neglect 41: 30-9.

Puma, Michael, Stephen Bell, Ronna Cook, Camilla Heid, Gary Shapiro, Pam Broene, Frank Jenkins, Philip Fletcher, Liz Quinn, and Janet Friedman. 2010. Head Start Impact Study. Final Report. In Administration for Children E Families; Washington: US Department of Health and Human Services.

Rabinradkumar, Sumi. 2018. One in four. A Profile of Single Parents in the UK. London: Gingerbread.

Racine, Andrew D. 2016. Child poverty and the health care system. Academic Pediatrics 16: S83-S89. [CrossRef] [PubMed]

Roberts, Helen. 2012. What Works in Reducing Inequalities in Child Health. Bristol: The Policy Press.

Robinson, Gareth. 2010. Media, Marketing and The Dole Cruisers-A Welfare Discourse Case Study. Master's thesis, University of Wollongong, Wollongong, Australia.

Schmuecker, Katie. 2017. Briefing for November 2017 Budget: Incomes Not Keeping up with Prices. Available online: https:/ / www.jrf.org.uk/report/briefing-november-2017-budget (accessed on 31 August 2018).

Sherman, Arloc, Brandon DeBot, and Chy-Ching Huang. 2016. Boosting low-income children's opportunities to succeed through direct income support. Academic Pediatrics 16: S90-S97. [CrossRef] [PubMed]

Smeeding, Timothy, and Céline Thévenot. 2016. Addressing child poverty: How does the United States compare with other nations? Academic Pediatrics 16: S67-S75. [CrossRef] [PubMed]

Taylor-Gooby, Peter, and Eleanor Taylor. 2014. Benefits and welfare: long-term trends or short-term reactions? In British Social Attitudes, 32nd ed. London: NatCen.

Thompson, Neil. 2016. Anti-Discriminatory Practice: Equality, Diversity And Social Justice, 6th ed. London: Palgrave Macmillan.

Timmins, Nicholas. 2016. Universal Credit. From Disaster to Recovery? London: Institute for Government.

Tinson, Adam, Hannah Aldridge, Theo Barry Born, and Ceri Hughes. 2016. Disability and Poverty. Why Disability must be at the Centre of Poverty Reduction. York: New Policy Institute.

Turcios, Eric. 2009. Remaining versus removal: Preventing premature removal when poverty is confused with neglect. Michigan Child Welfare Law Journal 12: 20-8.

Ward-Batts, Jennifer. 2008. Out of the wallet and into the purse. Using micro data to test income pooling. Journal of Human Resources 43: 325-51. [CrossRef] 
Wherry, Laura R., and Sarah Miller. 2016. Early coverage, access, utilization, and health effects associated with the Affordable Care Act Medicaid expansions: a quasi-experimental study. Annals of Internal Medicine 164: 795-803. [CrossRef] [PubMed]

Wilkinson, Richard, and Kate Pickett. 2006. Income inequality and population health: A review and explanation of the evidence. Social Science \& Medicine 62: 1768-84.

Wright Edelman, Marian. 2016. Ending childhood poverty in America. Academic Pediatrics 16: S6-7. [CrossRef] [PubMed]

Zilberstein, Karen. 2016. Parenting in families of low socioeconomic status: A review with implications for child welfare practice. Family Court Review 54: 221-31. [CrossRef]

2018 by the authors. Licensee MDPI, Basel, Switzerland. This article is an open access article distributed under the terms and conditions of the Creative Commons Attribution (CC BY) license (http://creativecommons.org/licenses/by/4.0/). 